\title{
Is knowledge of leprosy adequate among teachers? A comparative study
}

\author{
JOLLY RAJARATNAM, R. ABEL \& \\ MATHEW ARUMAI \\ RUHSA Department, Christian Medical College \& Hospital, Vellore, \\ India
}

Accepted for publication 30 November 1998

\begin{abstract}
Summary A cross-sectional comparative study on the levels of knowledge and attitude on leprosy among teachers and students was carried out in a rural area of Vellore district in Tamil Nadu, India. A total of 30 teachers and 120 students participated in the study. It was found that knowledge about leprosy among teachers was inadequate. Only $23.4 \%$ of teachers stated that germs caused leprosy, while $23.4 \%$ mentioned immoral conduct, $20.0 \%$ marrying a leprosy patient, $6.6 \%$ insects and $26.6 \%$ did not know the causes of leprosy. While $80.0 \%$ of teachers knew that anaesthetic hypopigmented patches were a sign of leprosy, enlarged painful nerves were not mentioned by a single teacher, although this sign was identified by $17.5 \%$ of students. Teachers had a more positive attitude towards leprosy than students and this was statistically significant $(p<0 \cdot 001)$. This paper discusses the need for continuous education, especially for teachers and through them the students, using different media so as to ensure sustained knowledge for behavioural change in the community.
\end{abstract}

\section{Introduction}

A lack of accurate knowledge about leprosy in the community may be an important factor in hindering leprosy control. Health education has been described as a central component of anti-leprosy activities which are promoted in many countries where the disease is endemic. ${ }^{1}$

Studies have assessed the knowledge and attitude of leprosy patients, ${ }^{2-4}$ the community, ${ }^{4-7}$ nurses $^{8}$ and doctors. ${ }^{7,9-11}$ A number of studies ${ }^{12-14}$ have documented the effectiveness of health education given on leprosy to school students. Mutatkar ${ }^{15}$ in his review stated that knowledge attitude practice studies indicated a lack of accurate knowledge about leprosy among the general population as well as patients.

In 1975, Gershon et al. ${ }^{16}$ studied the impact of health education programmes on the awareness and attitude of teachers regarding leprosy in Madras, Southern India. In 1976, Mutatkar ${ }^{7}$ selected teachers as one of the nine categories of people he had studied in both

Correspondence to: Dr Rajaratnam Abel, Head, Ruhsa Department, Ruhsa Campus PO 632 209, Vellore District, Tamil Nadu, India 
experimental and control areas of Poona and Jalgaon, in assessing the effectiveness of the health education programme of the National Leprosy Eradication Programme (NLEP) by the Gandhi Memorial Leprosy Foundation. Since then, there have been no studies on the knowledge levels of teachers. This indicates the lack of priority that health workers have given to this core group of teachers.

Another study ${ }^{17}$ was carried out in 1985 by RUHSA Department among teachers in a neighbouring area. A large proportion of the teachers were unaware of the cause, symptoms and communicability of leprosy, and prevention of deformity. This study compares the level of knowledge and attitude about leprosy among teachers and students.

\section{Materials and methods}

The study design was a cross-sectional knowledge, attitude and behaviour (KAB) survey of school teachers and students in K.V. Kuppam Block, Vellore District, Tamil Nadu, India. This is one of the three blocks in Gudiyatham Taluk, which is the leprosy control area of the Schieffelin Leprosy Research and Training Centre (SLR\&TC) at Karigiri, Vellore District. The prevalence of leprosy in the control area declined from $25 \cdot 8$ per 1000 in 1970 to $14 \cdot 2$ per 1000 in $1981 .^{18}$ It has decreased further to 11.44 per 1000 in 1986 and to 1.95 per 1000 in 1993. ${ }^{19}$

Out of nine high schools and two higher secondary schools in the block four high schools and one higher secondary school were randomly selected. From each school, 24 students were selected using systematic random sampling. There were 12 girls and 12 boys from each of the three mixed schools and 24 boys and 24 girls from each of the two single sex schools, respectively. Six teachers were randomly selected from each school. The total sample in this study consisted of 120 students and 30 teachers.

The variables studied were knowledge about cause, symptoms, spread, consequences, treatment and prevention of leprosy. Information on attitude and behaviour of students and teachers towards leprosy was also obtained. The perception of ideal treatment and actual practice was also studied.

The data were collected by one trained data collector using a pretested interview schedule. Quality control measures included cross-checking of 5\% samples, spot checks and editing $100 \%$ of the schedules. The data were analysed manually using percentages and chi-squares as the statistical measures.

\section{Results}

Interesting results were obtained from the comparison of knowledge, attitude and behaviour regarding leprosy between the students and teachers. The stark contrast can be seen in Table 1 . Among students, $57 \cdot 4 \%$ knew that germs cause leprosy, while only $23.4 \%$ teachers identified this correctly. This difference is statistically significant $(p<0.001)$. Among teachers, $23.4 \%$ and $20.0 \%$, respectively, identified insects and marrying a leprosy patient as causes. Finally, $26.6 \%$ of teachers had no idea of the cause of leprosy. The teachers' knowledge of the cause of leprosy was poorer than that of the students.

Most of the teachers $(80 \%)$ knew that anaesthetic hypopigmented patches were one of the symptoms of leprosy, while only $43 \%$ of students recognized this (Table 2). A variety of 
Table 1. Knowledge on cause of leprosy

\begin{tabular}{lrrrrr}
\hline & \multicolumn{2}{c}{ Students } & & \multicolumn{2}{c}{ Teachers } \\
\cline { 2 - 3 } \cline { 5 - 6 } & \multicolumn{2}{c}{$\%$} & & \multicolumn{1}{c}{$\%$} \\
Cause of leprosy & No. & $n=120$ & & No. & $n=30$ \\
\hline Germs & 69 & $57 \cdot 4$ & & 7 & $23 \cdot 4$ \\
Insects & 17 & $14 \cdot 2$ & & 2 & $6 \cdot 6$ \\
Immoral conduct & 17 & $14 \cdot 2$ & & 7 & $23 \cdot 4$ \\
Marrying a leprosy patient & - & - & & 6 & $20 \cdot 0$ \\
No idea & 17 & $14 \cdot 2$ & & 8 & $26 \cdot 6$ \\
Total & 120 & $100 \cdot 0$ & & 30 & $100 \cdot 0$ \\
& & & & & \\
\hline
\end{tabular}

symptoms, including loss of sensation in the hands and legs, enlarged painful nerves, enlarged ear lobes with loss of eyebrows and shining skin, were mentioned by the students. This is significantly more than what the teachers stated $(p<0.001)$. It is notable that none of the teachers cited enlarged painful nerves as one of the symptoms, whilst $17 \cdot 5 \%$ of the students mentioned this.

Regarding consequences, both groups identified the different consequences (Table 3). However, a notable finding was that $13.3 \%$ of the teachers indicated that there were no changes as a result of leprosy. Unlike the teachers, a significant proportion $(p<0.001)$ of the students knew that ulcers in hands and feet and chronic illness were consequences of leprosy.

The students attempted to answer questions on the mode of spread, with a number of them giving acceptable answers, e.g. physical contact $(24 \cdot 2 \%)$, staying in the infected patient's house $(25.9 \%)$, sneezing (46.0\%), cough (44.0\%) and soil (7.5\%). Unexpectedly, most of the teachers did not answer. Surprisingly, four teachers indicated that leprosy is spread by bad conduct.

Among the teachers, $66.7 \%$ were able to say that leprosy is not hereditary. A surprise finding was that $23.3 \%$ of the teachers stated that it was hereditary and $10 \%$ were totally ignorant. Among students, 56.6\% were ignorant.

All the teachers except one stated that leprosy was curable. Nearly $85 \%$ of the students also knew that it was curable. The source of treatment was correctly stated by $73 \cdot 3 \%$ of the teachers and $45 \%$ of the students. The teachers were generally aware that the allopathic system was the best for treatment. The students were not sure of treatment, but the majority recommended allopathy.

Table 2. Knowledge on signs and symptoms of leprosy

\begin{tabular}{|c|c|c|c|c|}
\hline \multirow[b]{2}{*}{ Signs \& symptoms } & \multicolumn{2}{|c|}{ Students } & \multicolumn{2}{|c|}{ Teachers } \\
\hline & No. & $\begin{array}{c}\% \\
n=120\end{array}$ & No. & $\begin{array}{c}\% \\
n=30\end{array}$ \\
\hline Anaesthetic hypopigmented patches in the body & 51 & $42 \cdot 5$ & 24 & $80 \cdot 0$ \\
\hline Loss of sensation of hands and legs & 41 & $34 \cdot 2$ & 6 & $20 \cdot 0$ \\
\hline Enlarged painful nerves & 21 & $17 \cdot 5$ & - & - \\
\hline Enlarged ear lobes with loss of eyebrows and shiny skin & 13 & $10 \cdot 8$ & 1 & $3 \cdot 3$ \\
\hline
\end{tabular}


Table 3. Knowledge on consequences of leprosy

\begin{tabular}{|c|c|c|c|c|}
\hline \multirow[b]{2}{*}{ Consequences } & \multicolumn{2}{|c|}{ Students } & \multicolumn{2}{|c|}{ Teachers } \\
\hline & No. & $\begin{array}{c}\% \\
n=120\end{array}$ & No. & $\begin{array}{c}\% \\
n=30\end{array}$ \\
\hline Deformities & 58 & $48 \cdot 3$ & 17 & $56 \cdot 7$ \\
\hline Ulcers in hands and feet & 26 & $21 \cdot 7$ & 2 & $6 \cdot 7$ \\
\hline Chronic illness & 38 & $31 \cdot 7$ & 3 & $10 \cdot 0$ \\
\hline Anaesthetic patches throughout the body & 4 & $3 \cdot 3$ & - & - \\
\hline No change & - & - & 4 & $13 \cdot 3$ \\
\hline
\end{tabular}

While knowledge on preventing deformities was relatively high among both teachers and students, over one-third of the students were ignorant in this area. Only $50 \%$ of students, but $90 \%$ of teachers, knew that deformities can also be treated. Teachers had a significantly $(p<0.001)$ positive attitude towards leprosy patients compared to students (Table 4$)$.

Cross-tabulation did not show any significant association between level of knowledge on leprosy and age, caste, father's and mother's education, years of education and years of experience as a teacher. However, there was a significant association $(p<0.05)$ between housing type (type of roof) and level of knowledge, with those students living in terraced and tiled houses having more knowledge than those living in thatched houses.

\section{Discussion}

Reviewing the literature, it was surprising to identify only two studies which measured teachers' knowledge of leprosy. In contrast, a number of studies were available on knowledge of leprosy among the target groups, such as students, parents and the general community. Mutatkar ${ }^{7}$ rightly pointed out in the 1970 s that teachers are an organized and powerful group in the community. They have a profound influence on their students. Teachers could have a significant role in teaching basic facts about leprosy, assisting diagnosis by identifying suspicious patches early, and helping to prevent victimization of leprosy-affected children.

The $\mathrm{WHO}^{20}$ Expert Committee has repeatedly recommended the training of various groups of personnel, including teachers, as health educators in leprosy. They are likely to

Table 4. Attitude towards leprosy

\begin{tabular}{|c|c|c|c|c|}
\hline \multirow[b]{2}{*}{ Attitude } & \multicolumn{2}{|c|}{$\begin{array}{c}\text { Students } \\
\text { Positive Response }\end{array}$} & \multicolumn{2}{|c|}{$\begin{array}{c}\text { Teachers } \\
\text { Positive Response }\end{array}$} \\
\hline & No. & $\begin{array}{c}\% \\
n=120\end{array}$ & No. & $\begin{array}{c}\% \\
n=30\end{array}$ \\
\hline Should leprosy patients be segregated from the community? & 41 & $34 \cdot 2$ & 19 & $63 \cdot 3$ \\
\hline Would you allow a leprosy patient to sit next to you? & 27 & $22 \cdot 5$ & 18 & $60 \cdot 0$ \\
\hline Would you eat in the house of a leprosy patient? & 18 & $15 \cdot 0$ & 16 & $53 \cdot 3$ \\
\hline Would you allow a leprosy patient to touch you? & 26 & $21 \cdot 7$ & 17 & $56 \cdot 7$ \\
\hline
\end{tabular}


increase the health consciousness of the students. WHO has also recommended that attention be directed at Teacher Training Centres.

In the Mutatkar ${ }^{7}$ study, the education programme consisted of two lectures and one slide show for the teachers of Poona, the experimental group. Even the study ${ }^{16}$ on teachers carried out in Tamil Nadu measured their knowledge after only $3 \mathrm{~h}$ of a single session of teaching on leprosy. Although there were statistical differences between the teachers of Poona and Jalgaon, there was too little change, even in Poona, for a true comparison. Only $9.2 \%$ of teachers in Poona after education knew that leprosy was caused by germs, as opposed to $4 \cdot 3 \%$ in Jalgaon. In the Gershon ${ }^{6}$ study, of those stating germs as the cause, an increase from $7 \cdot 1 \%$ to $68 \%$ was observed among teachers between pre- and post-evaluation. In the present study, $23.4 \%$ of teachers and $57.4 \%$ of students were aware of germs as a cause of leprosy. Further, $40.8 \%$ teachers in Poona, and $51.8 \%$ in Jalgaon stated that leprosy is hereditary, whereas in the Gershon study it was $23.5 \%$ before education and nil after education. In the present study, $23.3 \%$ teachers stated that it was hereditary.

Bhore et $a l .{ }^{12}$ have found that child-to-parent education may show promising results in leprosy education in developing countries. In this setting, most parents of school children are illiterate and are not easily reached by conventional methods of health education. Jacob's ${ }^{13}$ study also confirms this. Another study carried out by Prem Kumar et al. ${ }^{14}$ did not show a significant transfer of knowledge through students to their parents. The authors themselves accepted the limitation of a small sample size and no instructions being given to the children to pass on the message. There was only one education session. However, it was observed in another study from Tamil $\mathrm{Nadu}^{21}$ that when teachers and students were systematically taught any health education message, they were able to transfer their knowledge to their parents.

In the earlier studies ${ }^{12,16}$ quoted, it has been observed that after obtaining the preprogramme level of knowledge of students, health educators were used to teach the students on leprosy. On the other hand, if they had taught the teachers, the educational process could have been sustained over a much longer period.

The NLEP of India has found a low correlation between knowledge and attitude among the community with relation to leprosy. ${ }^{22}$ The study by Raju and Koparty ${ }^{5}$ in Andhra Pradesh and Orissa States in India showed that in Andhra, 50\% of the respondents had a high knowledge level; however, only $25 \%$ had a positive attitude towards leprosy, indicating that good knowledge and a positive attitude do not necessarily go together. However, in Orissa almost all respondents had a negative attitude towards leprosy. In the present study, even though the teachers had low levels of knowledge, they had high positive attitudes.

Teachers can play a vital role in leprosy education, as the majority of the community passes through the school system. Teachers' knowledge and attitude should be sound enough to bring about a behavioural change among the students. It is necessary to carry out similar studies on teachers in other parts of the state and country, relating not only to leprosy but other diseases such as tuberculosis, cancer and AIDS. If the findings are similar, then serious efforts must be made to educate teachers about the commonly prevalent diseases. If teachers, the key educators in any country, are ignorant about diseases like leprosy, then we cannot expect rapid changes in early diagnosis and treatment. It has been proved that when teachers are correctly educated, they can effectively transfer this knowledge through the school children to their parents. $^{21}$

In conclusion, it can be stated that while health service providers, including health educators and social workers, can bring about behaviour changes in target groups, only teachers can bring about this change in the community as a whole through the school 
children. However, to bring about this change, teachers need to be trained over a period of time, using different media so that they can retain the knowledge gained and pass on the messages relating to leprosy and other diseases to students in an ongoing sustainable manner.

\section{References}

I Mehendale MS. Health Education in leprosy. In: A manual of leprosy, Thangaraj RH (ed.). The Leprosy Mission, New Delhi, 1987, Chapter 22, 372-394.

2. Raj V, Garg BR, Lal S. Knowledge about leprosy among leprosy patients. Lepr India, 1981; 53: $226-230$.

3 Kumar RK, Ramaniah TBBSR, Jessie FSNKB, Sabhesan S. Level of knowledge of leprosy patients towards their ailment. Lepr India, 1983; 55: 107-110.

4 Myint T, Thet AT, Htoon MT, Win M. A comparative KAP study of leprosy patients and members of the community in Hlaing and Laung-Lon Townships. Ind J Lepr, 1992; 64: 313-322.

5 Raju MS, Kopparty SNM. Impact of knowledge of leprosy on the attitude towards leprosy patients: a community study. Ind J Lepr 1995; 67: 259-271.

6 Tekle-Haimont R, Forsgren L, Gebre-Mariam A et al. Attitudes of rural people in Central Ethiopia towards leprosy and a brief comparison with observation on epilepsy. Lepr Rev, 1992; 63: 157-168.

7 Mutatkar RK. Society and leprosy. Gandhi Memorial Leprosy Foundation, Sharad Gogate Publishers, 1979: 29, 35, 37.

8 Awofeso N. Appraisal of the knowledge and attitude of Nigerian nurses toward leprosy. Lepr Rev, 1992; 63: 169172.

${ }^{9}$ Uplekar MW, Cash RA. The private GP and leprosy: a study. Lepr Rev, 1991; 62: 410-419.

${ }^{10}$ Ramanathan U, Ramu G. Attitude of doctors to working in leprosy. Lepr India, 1982; 54: 695-699.

11 Sandhu HS. Knowledge, attitude and practice of leprosy among doctors in Bhopal. Ind J Lepr, 1984; 56: 633-640.

12 Bhore PD, Bhore CP, Powar S et al. Child to parent education. A pilot study. Ind J Lepr, 1992; 64: 51-57.

13 Jacob MS, Amar D, Christopher A, Keystone JS. Transmission of health information on leprosy from children to their families in an urban centre. Lepr Rev, 1994; 63: 272-278.

14 Prem Kumar R, Keystone JS, Christian M, Jesudason K. Transmission of health information on leprosy from children to their families: another approach to health education. Lepr Rev, 1991; 62: 58-64.

15 Mutatkar RK. Social science research on leprosy: a review. In: Social science research and social action for leprosy control, Srinivasan H (ed.). Indian Association of Leprologists, 1991: 98.

16 Gershon W, Mani RS, Roopkumar KSB. Programme for Health Education among school teachers. A study conducted at GREMALTES. Lepr India, 1981; 53: 641-655.

17 Sivasankaran S. Field study report on knowledge and perception of school teachers on leprosy. RUHSA Central Library D-03, FSR-15, 1985-86: 1-41.

18 Christian M, Rao PSS, Pannikar VK. Epidemiology of leprosy in Gudiyatham Taluk. Ind J Lepr, 1984; 56: 687688.

19 Jesudasan K, Rao PSS, Jayaraj T, Raja Samuel JD. Changes in prevalence of leprosy in different clinic areas of Gudiyatham Taluk 1970-1993. Ind J Lepr, 1994; 66: 359.

20 WHO. Fourth report of expert committee on leprosy. Tech Rep Services, 1970: 459.

21 Saminathan P, Ravindranath MJ, Abel R. Health Messages for adults—from their children. World Health Forum, 1986; 7: 191-193.

22 Mutatkar RK, Ranade MG. Evaluation of Health Education in leprosy control programme: methodological considerations. SE Asia J Trop Med Public Health, 1986; 77: 437-441. 